\title{
Application of an Artificial Neural Network in Pavement Management System
}

\author{
Josipa DOMITROVIĆ, Hrvoje DRAGOVAN, Tatjana RUKAVINA, Sanja DIMTER
}

\begin{abstract}
The era of intensive construction of new roads in Croatia is behind us. Today road agencies are focused on maintaining and preserving existing roads. Selection of an appropriate maintenance strategy is a complex task, which includes factors such as the current condition of the pavement, road classification, traffic volume etc. These factors are usually implemented in pavement management systems. The key components of pavement management systems are pavement performance prediction models such as artificial neural networks. This paper analyses the possibility of using artificial neural networks to evaluate existing pavement condition, and its possible application for defining the maintenance strategy of national roads. A backpropagation neural network was applied on $481.3 \mathrm{~km}$ of national roads in the Osijek-Baranja County. The obtained results indicated that artificial neural networks could be used for optimization of maintenance or rehabilitation strategies, and for the assessment of pavement condition at the project and network level.
\end{abstract}

Keywords: artificial neural network; backpropagation algorithm; pavement maintenance; pavement management system

\section{INTRODUCTION}

Every pavement, no matter how well designed and/or constructed, will deteriorate over time [1]. Pavement deterioration is influenced by the traffic load, climate conditions, quality of construction, layer thicknesses and the quality of previous maintenance and rehabilitation activities. The rate of deterioration as a function of above mentioned factors and time is not linear. Normally, during the first $50-75 \%$ of designed life, pavement condition remains good and the deterioration processes are progressing slowly. Once pavement condition begins to decrease deterioration processes are progressive and rapid $[2,3]$. Appropriate maintenance or rehabilitation activities, if applied in timely manner, can slow down or reset pavement degradation processes.

Over the past twenty years, it has been observed that the existing, classical experience in road maintenance is insufficient, and that new methods of data collection and processing are being introduced into pavement management [4]. Through the accelerated development of information technology and artificial intelligence, unlimited opportunities are opening for their implementation in pavement engineering.

An artificial neural network is a form of artificial intelligence that might be applied for solving nonlinear engineering problems like prediction and estimation, pattern recognition and optimization $[5,6]$. One such problem is selection of pavement maintenance strategy that is essentially based on human expertise and knowledge. Alsugair and Al-Qudarh [7] cited four reasons that justify the use of neural networks in pavement management systems and these are: 1) selection of appropriate strategy is not based on algorithmic procedures and mathematical formulas; 2) road conditions are numerically represented by densities and severity level of each distress type; 3 ) road condition for selection of appropriate strategy is not strictly defined; and 4) selection of strategy is not justified only on the basis of statistical data.

In this paper a short state of the art in the area of application of artificial neural network in pavement engineering is given, followed by basic description of backpropagation ANN as most commonly applied network in this area. Paper further analyses the possibilities of using artificial neural networks to evaluate existing pavement condition and to select the optimal pavement maintenance strategy on data collected from national road network in Croatia.

\section{STATE OF THE ART}

Artificial neural networks (ANN) in pavement management systems (PMS) can be used for estimating current and predicting future pavement condition as well as for assessing maintenance needs and selecting maintenance strategies [4]. Several studies dealing with application of ANN for various tasks in the frame of PMS are summarized in this section.

Possibility of using ANN as a tool for screening and condition rating of pavement was studied by Eldin and Senouci [8]. They developed neural network system for the determination of flexible pavements condition rating based on cracking and rutting indices. Conducted study shows that neural networks are capable of accurately determining pavement condition rating in a systematic and objective manner. Van der Gryp et al. [9] evaluate the capabilities of neural networks in determining the visual condition index (VCI) of flexible pavements, using distress data collected through visual assessments. Research was conducted on feed-forward artificial neural network with one hidden layer. Obtained results indicate that application of ANN is a feasible method for determining VCI and its main advantage lies in objectivity.

Positive results on ANN application for evaluation of present pavement performance have encouraged researchers in the application of neural networks for prediction tasks. A large number of researchers deal with developing pavement distress prediction models. These models are aimed at predicting progression of single distress (e.g. cracks, roughness, rutting) or combination of various distresses through pavement performance indicator.

Thube [10] in his study suggested four unified ANN models to predict the progression of different pavement distresses (cracking, raveling, rut depth and roughness) on low volume roads. Obtained results indicate high correlation between observed and ANN predicted distresses. The results showed that suggested ANN models 
would be useful in the accurate prediction of investigated distresses.

Yang et al. [11] developed three individual ANN models for prediction of three key indices, crack rating, ride rating, and rut rating used by Florida Department of Transportation for pavement evaluation purposes. Results of the combination of the individual models suggest that the developed ANN models have the capability to satisfactorily forecast the overall pavement condition index up to a future period of five years.

Huang and Moore [12] studied roughness level probability prediction using multiple linear regression and two ANN. Obtained results indicate that ANNs have a superior ability to predict the probability of roughness distress level compared with multiple regression methods. Lin et al. [13] constructed back-propagation ANN for prediction of International Roughness Index (IRI) based on distress rating results obtained from pavement video images. Results of conducted study showed high correlation between IRI and the distress variables, which lead to a conclusion that IRI may completely reflect pavement distress conditions. Correlating the pavement roughness to other performance measures was studied by Mazari and Rodriguez [14]. They proposed methodology which included the application of a hybrid technique which combines the gene expression programming (GEP) and artificial neural network (ANN). The developed algorithm showed good results for prediction of IRI using traffic parameters and structural properties of pavement.

The use of ANN for screening and recommending road sections for pavement preservation program was evaluated by Flintsch et al. [15]. Based on the research it was concluded that ANN reduces the level of effort required to identify sections for the pavement preservation program and reduces subjectivity and it was recommended to evaluate the possibility of using ANN for selection of preservation treatments. Abdelrahim and George [16] evaluate the use of ANN to predict the optimum maintenance strategy on the basis of realistic (noisy) data. They concluded that ANN provides an efficient and optimum solution with the added advantage of fast implementation and easy updating. Positive experience of ANN application in pavement management decision support system to recommend appropriate maintenance and rehabilitation actions was reported by Alsugair and AlQudarh [7].

Mosa [17] proposed a system based on neural network technique to diagnose the pavement distresses and to optimize the solutions for recommendation of maintenance method and materials. The developed system provided optimum solution considering technical, economical, and environmental factors.

Gebely [18], in his master thesis, developed two ANNbased maintenance decision models. Results of this study reveal that ANN is appropriate for implementation in recommending current and future flexible pavement maintenance decision.

Based on conducted literature review it can be concluded that ANN have the potential to investigate and properly model complex, non-linear pavement engineering problems. Most of the reviewed studies employed backpropagation ANN and since this type of network was used in a study presented in the paper, its basic principles are described in the following section.

\section{BACKPROPAGATION ARTIFICIAL NEURAL NETWORK}

Backpropagation artificial neural networks are one of the most commonly used networks. They are very powerful and versatile networks that can be learned to copy from one data space to another using a representative set of examples [19]

The structure of a backpropagation neural network consists of two external layers (input and output) and one or more hidden layers (Fig. 1). The network receives data by neurons in the input layer. The result of the network is given by neurons in the output layer [20]. The hidden layers examine the interdependencies in the model and process the information.

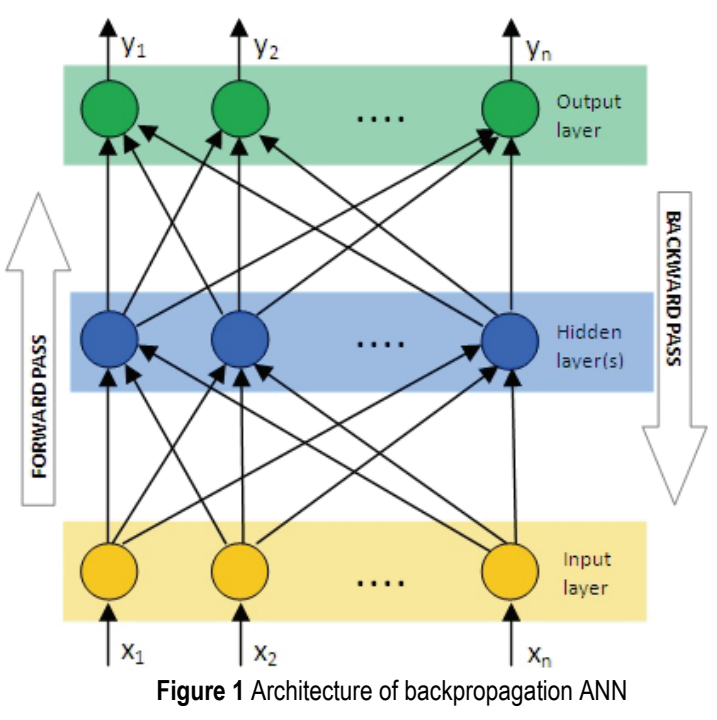

The neural network is defined through two phases, the learning or training phase and the testing phase. Prior to learning, it is necessary to define the input and output variables and to collect data to which the backpropagation algorithm will be applied [21].

The backpropagation algorithm uses supervised learning, which means that we provide the network with examples of inputs and outputs [22, 23]. During the training phase, information is transferred in a forward and backward pass. In the forward pass random weights are assigned to input values and propagated forward through the network to calculate the output. In the backward pass the calculated output is compared with the desired output and the difference, i.e. the error, is computed. During the backward pass, weights are modified to reduce the error. The scaling of local error and the increase or decrease of the weight is calculated for each layer, beginning with the layer directly under the output layer, back to the first hidden layer. The described learning process is repeated in multiple iterations. Learning is stopped when the error reaches a previously specified minimum value [24].

In the testing phase, the weights are fixed according to the values obtained in the learning phase. New input data that have not participated in the learning process are presented to the network. The output from the network is compared with the desired output and the error is 
calculated. Depending on the size of the calculated error, an assessment is made of the possible application of the ANN.

\section{PREPARATION OF THE DATABASE}

Before the application of an ANN it was necessary to collect and sort the data on which network would conduct learning and training.

Measurements of various types of pavement technical parameters (longitudinal evenness, rut depth, texture depth, surface cracks and patches) were conducted on national roads in the Osijek - Baranja County with a total length of $481.3 \mathrm{~km}$, which represents $7 \%$ of the national road network in Croatia (Fig. 2). The collected data were divided into segments of $1 \mathrm{~km}$ length, forming a road database with a total of 471 samples. Road database is divided in three mutually connected bases: initial calculation database (ICD), strategy determination database (SDD) and neural network initial database (NNID).

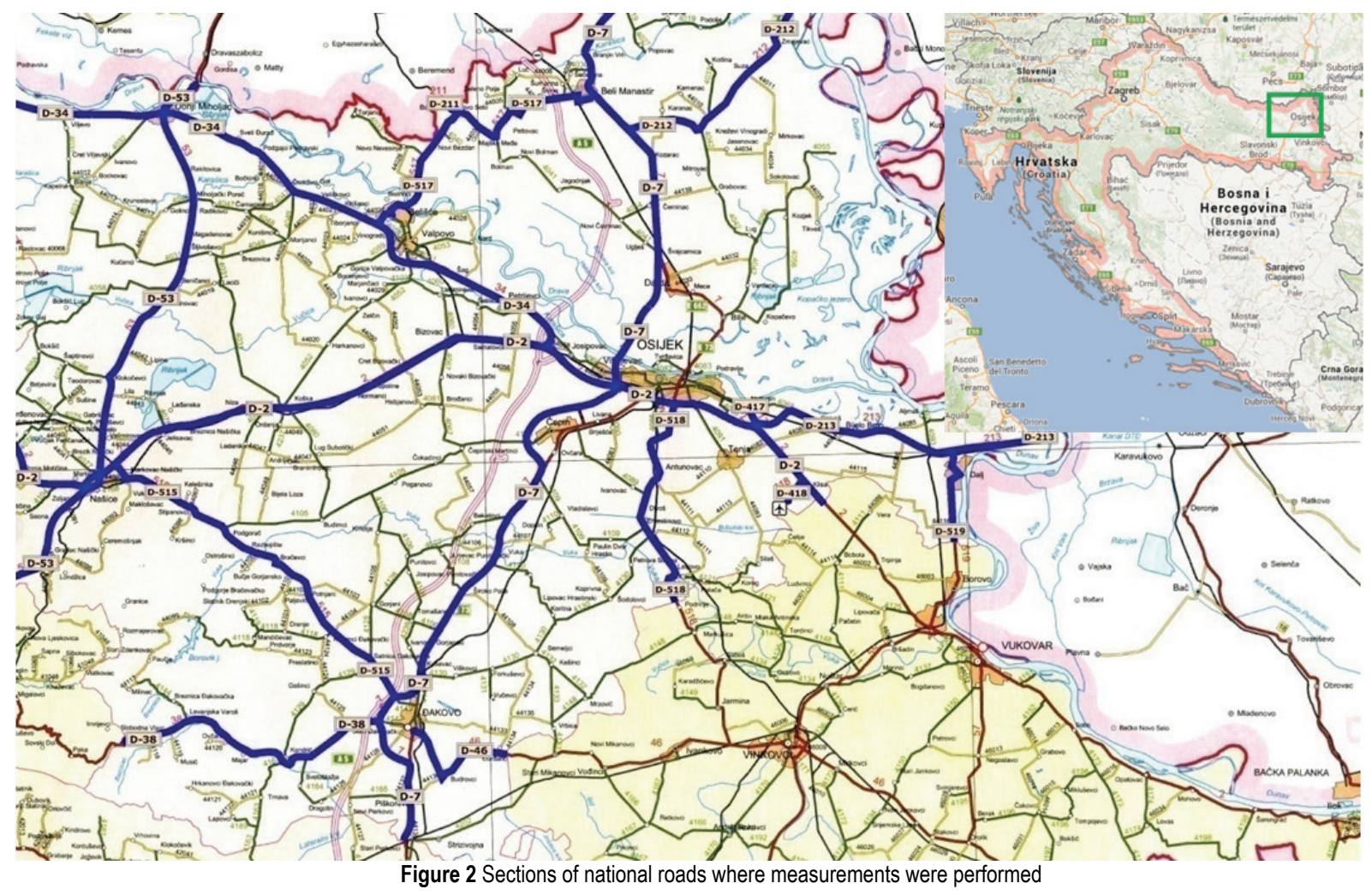

\subsection{Initial Calculation Database (ICD)}

The initial calculation database (ICD) is designed as a block database from which the mean value of an individual measurement parameter for each road segment is calculated from the input data.

Input data consisted of several pavement technical parameters (TP), i.e. International Roughness Index (IRI) as a measure of pavement longitudinal evenness, rut depth $(R D)$ for defining pavement transversal evenness, texture depth expressed by Mean Profile Depth $(M P D)$ for characterization of surface texture roughness, and cracks $(C R)$ and patches $(S D)$ expressed by percentage of affected surface area as a measure of pavement surface damage.

Individual mean values of technical parameters were converted into a non-dimensional performance indicator $(P I)$ through selected transformation function for national roads that are shown in Tab. 1. Calculations of individual, combined and general performance indicators were done according to COST Action 354 Guidelines [25] and Internal Guidelines of Croatian Roads [26].

COST Action 354 Guidelines [25] were developed at European level to define unique approach for pavement condition evaluation. Performance indicators are defined as a superior term of a technical road pavement characteristic, which can classify its condition [25, 27]. Guidelines define the procedure for calculation of pavement performance indicators that could be applied in different ways, depending on the type of measurements available and the analysis approach already in place in a given road authority. COST Action 354 Guidelines [25] with some adjustments are implemented into Internal Guidelines of Croatian Roads [26] and Management System of Croatian Motorways [28]. Calculation of combined and general performance indicators for Croatian national roads as suggested by Dragovan [29] is described below.

Table1 Selected transformation functions [29]

\begin{tabular}{|l|c|c|}
\hline \multicolumn{1}{|c|}{ TP } & $P I$ & Transformation function \\
\hline$I R I(\mathrm{~mm} / \mathrm{m})$ & PI_E & $0.1733 \times I R I^{2}+0.7142 \times I R I-0.0316$ \\
\hline$R D(\mathrm{~mm})$ & PI_R & $-0.0015 \times R D^{2}+0.2291 \times R D$ \\
\hline$M P D(\mathrm{~mm})$ & PI_T & $6.6-5.3 \times M P D$ \\
\hline$C R\left(\% / \mathrm{m}^{2}\right)$ & PI_CR & $0.1333 \times C R$ \\
\hline$S D\left(\% / \mathrm{m}^{2}\right)$ & PI_SD & $0.1333 \times S D$ \\
\hline
\end{tabular}

Calculation of the values of the global performance index $(G P I)$ is made in several steps. Groups of individual performance indicators corrected by weight create a 
combined non-dimensional performance indicator $(C P I)$ for the safety, comfort, and structural condition of the pavement. To calculate the $C P I$, the general expression is used:

$$
C P I=\min \left(5 ; I_{1}+\frac{p}{100} \times \mu\left(I_{2}, I_{3}, \ldots, I_{n}\right)\right),
$$

where $I_{n}$ is a weighted $P I$ that represents the influence of $P I_{n}$ in the $C P I, p$ is the influence factor that controls the total influence of the weighted performance indices for this study the value $20 \%$ is adopted, $I_{1}$ is the maximum weighted $P I$ and $\mu\left(I_{2}, I_{3}, \ldots, I_{n}\right)$ is the average value of the remaining weighted $P I$. Adopted weights of performance indicators for calculation of CPI in this study were taken from [29] and are given in Tab. 2.

Table2 Weights for the calculation of CPI [29]

\begin{tabular}{|c|c|c|c|}
\hline \multirow{2}{*}{$\begin{array}{c}\text { Performance } \\
\text { Indicator }\end{array}$} & \multicolumn{3}{|c|}{ Weights } \\
\cline { 2 - 4 } & $C P I_{\text {comfort }}$ & $C P I_{\text {safety }}$ & $C P I_{\text {structural }}$ \\
\hline PI_E & 1 & 0 & 0.6 \\
\hline PI_R & 0.7 & 1 & 0.5 \\
\hline PI_T & 0.4 & 0.67 & 0 \\
\hline PI_CR & 0.5 & 0 & 1 \\
\hline PI_SD & 0.6 & 0.67 & 0 \\
\hline
\end{tabular}

The CPIs corrected by the factor of the weight are joined in a non- dimensional global performance index (GPI) which represents an estimate of the condition of the pavements individual segments. The following equation was used to calculate the GPI:

$G P I=\min \left(5 ; I_{1}+\frac{p}{100} \times \frac{I_{2}+I_{3}}{2}\right)$,

where $I_{1}\left(I_{1}=1 \times C P I_{\text {safety }}\right)$ is a weighted safety $C P I$ that represents the maximum influence on the GPI, $I_{2}\left(I_{2}=0.7\right.$ $\left.\times C P I_{\text {comfort }}\right)$ and $I_{3}\left(I_{3}=0.8 \times C P I_{\text {structure }}\right)$ are weighted $C P I$ of remaining $C P I, p$ is the influence factor that controls the total influence of the weighted $C P I$ for this calculation the value $20 \%$ is adopted. Weights and influence factor of $C P I$ for calculation of GPI in this study were adopted from [29].

The condition of the pavement is determined based on the adopted criteria shown in Tab. 3 and the global performance index.

Table 3 Criteria for estimating pavement condition [25]

\begin{tabular}{|l|c|c|c|c|c|}
\hline \multirow{2}{*}{$\begin{array}{l}\text { Technical } \\
\text { parameter }\end{array}$} & \multicolumn{5}{|c|}{ Pavement condition rating } \\
\cline { 2 - 6 } & 1 & 2 & 3 & 4 & 5 \\
\hline IRI (m/km) & $0-1,1$ & $1,1-1,9$ & $1,9-2,6$ & $2,6-3,2$ & $3,2-3,7$ \\
\hline $\begin{array}{l}\text { Rut depth } \\
(\mathrm{mm})\end{array}$ & $0-4,5$ & $4,5-9,3$ & $9,3-14,5$ & $14.5-20,1$ & $20,1-26,4$ \\
\hline MPD $(\mathrm{mm})$ & $1,25-1,06$ & $1,06-0,87$ & $0,87-0,68$ & $0,68-0,49$ & $0,49-0,30$ \\
\hline $\begin{array}{l}\text { Cracks } \\
\left(\% / \mathrm{m}^{2}\right)\end{array}$ & $0-1$ & $1-10$ & $10-30$ & $30-50$ & $>50$ \\
\hline $\begin{array}{l}\text { Patches } \\
\left(\% / \mathrm{m}^{2}\right)\end{array}$ & $0-1$ & $1-10$ & $10-30$ & $30-50$ & $>50$ \\
\hline
\end{tabular}

An output result of the initial calculation database is the global performance index, which is entered into the neural network as one of the output data.

\subsection{Strategy Determination Database (SDD)}

The database for determining a strategy for maintaining a pavement contains within itself the implemented initial calculation database in a way that decisions on the selection of individual maintenance strategies depend on an evaluation of the pavement condition according to adopted criteria (Tab. 3, Tab. 4).

The maintenance strategy (MS) defines the type of pavement repair with the goal of increasing its load-bearing capacity, safety and comfort of driving.

Table4 Criteria for determining a maintenance strategy [29]

\begin{tabular}{|c|c|c|c|c|c|}
\hline \multirow{2}{*}{$\begin{array}{c}\text { Selected } \\
\text { MS }\end{array}$} & \multicolumn{5}{|c|}{ Rating of input technical parameters (as defined in $I C D$ ) } \\
\cline { 2 - 6 } & $I R I$ & Rutting & $M P D$ & Cracks & Patches \\
\hline MS_1 & $1 \& 2$ & 1 & $1 \& 2$ & 1 & 1 \\
\hline MS_2 & 3 & 2 & 3 & 2 & $2 \& 3$ \\
\hline MS_3 & 4 & $3 \& 4$ & 4 & $3 \& 4$ & 4 \\
\hline MS_4 & 5 & 5 & 5 & 5 & 5 \\
\hline
\end{tabular}

The following strategies have been defined and adopted for this study:

MS_1 - Routine maintenance of the pavement asphalt wearing course.

MS_2 - Improvement of the pavement surface by laying a new, thin asphalt wearing course of an appropriate depth.

MS 3 - Repair of cracks and correction of the longitudinal and transverse evenness by strengthening the existing pavement with new asphalt layer(s) of an appropriate depth.

MS_4 - Pavement rehabilitation, replacement of the existing pavement will be done with one of the following procedures: cold recycling, complete removal of the existing pavement, or strengthening of the pavement with the sandwich system.

\subsection{Neural Network Initial Database (NNID)}

The database for entry in the neural network is comprised of a set of input data and a set of output data. The input data are the measured values of the technical parameters (IRI, rut depth, texture depth, surface cracks and patches) shown as their mean value for an individual pavement segment. The results calculated global performance index $(G P I)$ and the selected maintenance strategy represent the output results of this database. The intention of this database is the preparation and sorting of data in a format suitable for entering it into the neural network.

The database for entry into the neural network is reduced by a randomly selected sample of $10 \%$ that is used to calculate the output results in the evaluation phase, and the neural network is presented with a total of 421 samples.

\section{APPLICATION OF ANN}

For the purpose of this study, a neural network with a backpropagation algorithm and different activation functions was applied in the software package NeuroShell 2.0 .

The data from the reduced neural network database were divided into two groups: a series of data in which the neural network conducts learning on $80 \%$ of the randomly 
selected data, while the remaining $20 \%$ form the control group on which testing of the network is performed.

The configuration of the selected neural network is shown in Fig. 3.

The inputs and outputs of the neural network are connected by two hidden layers. The input layer (slab 1) contains five neurons, each of which represents one input parameter. In the first hidden layer, there are two elements (slab 2 and slab 3) with eight neurons each, while the second hidden layer contains slab 4, which also has eight neurons. The output layer (slab 5) contains two neurons, which corresponds to the number of output data.

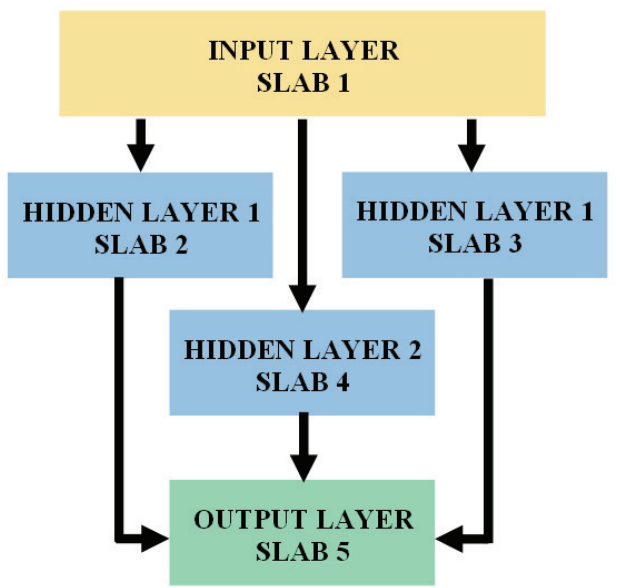

Figure 3 Schematic overview of the applied ANN

Neurons of the input layer are connected to each of the total 24 neurons in both hidden layers, and all neurons of the hidden layers are connected to neurons of the output layer.

The function applied to inputs to form the input activation level is a linear function. The function that results in the transfer of processed data for slabs 2 and 4 is a Gaussian function; for slab 3 it is the hyperbolic tangent function, while for the output layer it is logistic function.

\subsection{Learning Phase}

In the first iteration of the learning phase the initial weight 0.3 was assigned to all input data. By applying a backpropagation algorithm with a learning rate 0.1 and momentum 0.1, the weights are adjusted until the difference between output of the neural network and the desired output reached a minimum value [29].

The weights adopted at the end of the learning phase are shown in Tab. 5.

Table 5 Weights adopted by ANN

\begin{tabular}{|c|c|c|c|c|c|}
\hline \multirow{2}{*}{$\begin{array}{c}\text { Adopted } \\
\text { weights }\end{array}$} & \multicolumn{5}{|c|}{ Technical parameter } \\
\cline { 2 - 6 } & IRI & Rut depth & Texture depth & Cracks & Patches \\
\hline$G P I$ & 0.19 & 0.29 & 0.12 & 0.18 & 0.20 \\
\hline MS & 0.35 & 0.20 & 0.09 & 0.18 & 0.15 \\
\hline
\end{tabular}

In determining the global performance index of the network, the greatest weighting factor is given to the rut depth (0.29), which is in accordance with Cost Action 354 Guidelines [25], according to which the evaluation of pavement condition to a great extent can be shown by rut depth.
According to the network's understanding, the main factor for selecting the maintenance strategy is the value of IRI and it is given the greatest weighting factor (0.35), while texture depth has the least influence with a weighting factor of 0.09 .

\subsection{Testing Phase}

After the learning phase, the neural network was subjected to testing. In testing phase, weights were fixed to values adopted at the end of learning phase. New set of input and output data was presented to the network. Network output results were compared with desired output and statistically analyzed. The results of statistical analysis of output data are shown in Tab. 6.

Based on the results, it is evident that there is a high coefficient of correlation between the results obtained in the calculation of the neural network and the desired outputs. The percentage of data that the neural network has calculated within an accuracy of 5\% (79.42\% for calculating the maintenance strategy and $89.62 \%$ for calculating the global performance index) is satisfactory for the problem under consideration [29].

\begin{tabular}{|l|c|c|}
\hline \multicolumn{1}{|c}{ Table 6 Results of statistical analysis in testing phase } \\
\begin{tabular}{|l|c|c|} 
Criteria \\
Critical Comparison
\end{tabular} & $\begin{array}{c}\text { Global Performance } \\
\text { Index }(G P I)\end{array}$ & $\begin{array}{c}\text { Pavement } \\
\text { Maintenance } \\
\text { Strategy (MS) }\end{array}$ \\
\hline $\begin{array}{l}\text { Coefficient of } \\
\text { determination }\end{array}$ & 0.9678 & 0.9547 \\
\hline Mean square error & 0.031 & 0.023 \\
\hline Mean absolute error & 0.066 & 0.099 \\
\hline Coefficient of correlation & 0.9851 & 0.9796 \\
\hline Data accuracy within 5\% & 89.623 & 79.245 \\
\hline
\end{tabular}

Based on the obtained results, the neural network was accepted for solving the problem of determining the general performance index and selecting the optimal maintenance strategy.

\section{EVALUATION OF ANN}

A new set of data, the remaining $10 \%$ of the previously selected samples (47 samples) were presented to neural network defined in the previous section. In this step only the input data of the mean values of the technical parameters (IRI, rut depth, texture depth, cracks and patches) were processed. In this way, the network was given the opportunity to determine the output data (global performance index - GPI and maintenance strategy - MS) on the basis of previous "experience".

\begin{tabular}{|l|c|c|}
\multicolumn{1}{|c|}{ Table 7 Results of statistical analyses for ANN evaluation } \\
\begin{tabular}{|l|c|c|} 
Statical comparison \\
criteria
\end{tabular} & $\begin{array}{c}\text { General } \\
\text { Performance } \\
\text { Indicator }(G P I)\end{array}$ & $\begin{array}{c}\text { Pavement } \\
\text { maintenance } \\
\text { strategy (MS) }\end{array}$ \\
\hline Coefficient of determination & 0.9944 & 0.8629 \\
\hline Coefficient of correlation & 0.9972 & 0.9289 \\
\hline Maximum absolute error & 0.262 & 1.032 \\
\hline Accuracy rate \% & 87.234 & 95.745 \\
\hline
\end{tabular}

Fig. 4 and 5 show the relationship between the output results calculated by the neural network and the desired output results.

The results of the applied statistical criteria for evaluating the selection of a pavement strategy and 
calculation of general performance index are shown in Tab. 7.

Rounding off the values of the global performance index calculated by the neural network to the third decimal and comparing them to the desired outputs it was established that the neural network incorrectly calculated the GPI values in six cases. Based on this comparison, it can be stated that the neural network correctly predicted the values of the global performance index of a pavement in $87 \%$ of the cases (Fig. 4 ).

Rounding off the values of the results of the maintenance strategy into full numbers (from 1 to 4 ) and comparing those results with the actually selected maintenance strategy established that the neural network erred in calculating the type of strategy in two examples. In other words, the network will accurately determine the maintenance strategy in $95 \%$ of the cases (Fig. 5).
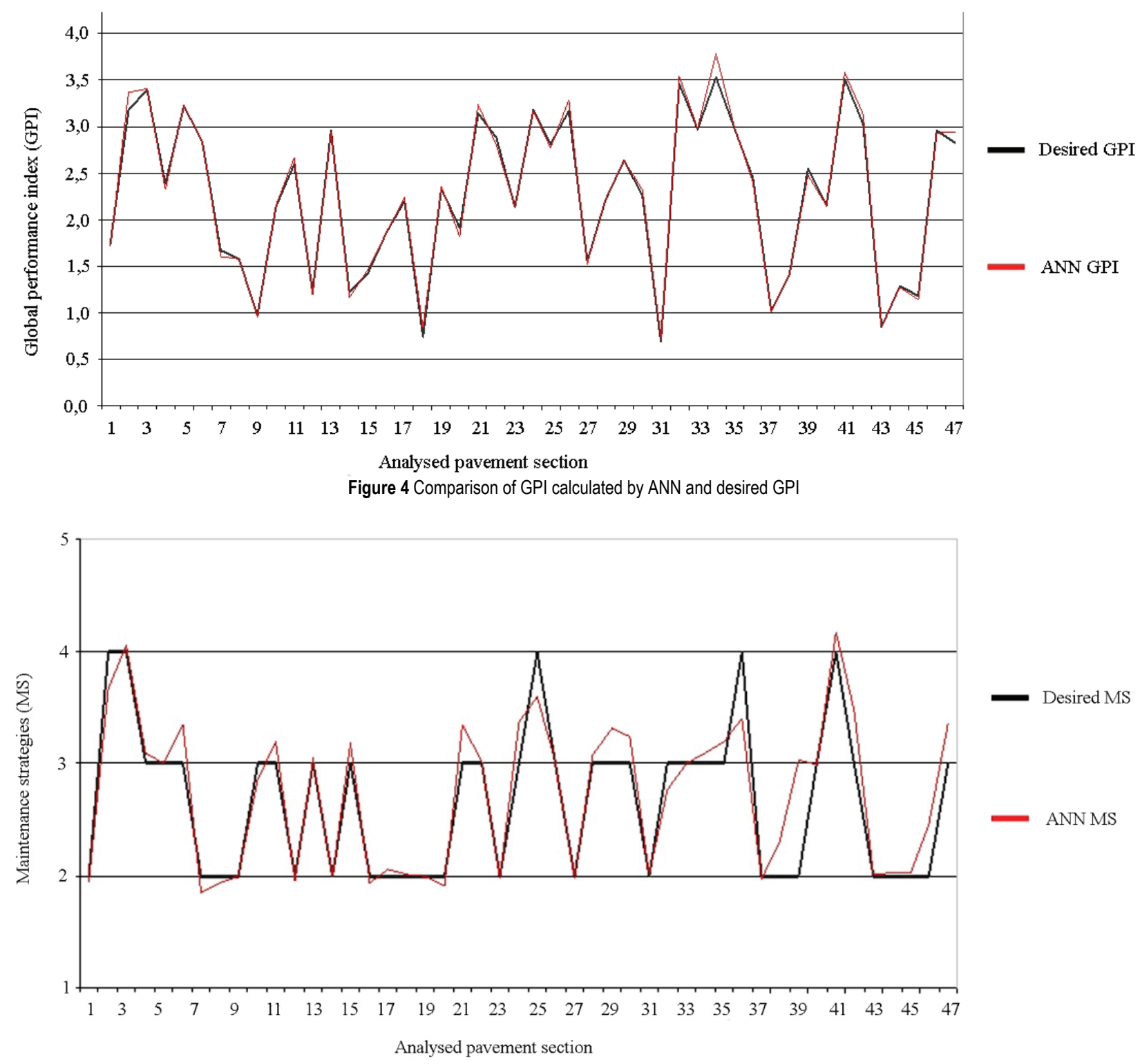

Figure 5 Comparison of MS selected by ANN and desired MS

\section{CONCLUSIONS}

The primary tasks of the pavement management system are pavement distress data collection, assessment of pavement condition through an analysis of the collected data, and selection of the optimal maintenance strategy. This paper examines the possibilities of using artificial neural networks to determine the global performance indicator and selecting the appropriate pavement maintenance strategy.

A neural network with a backpropagation algorithm was selected as part of the software package NeuroShell 2.0. The neural network was applied to a group of data obtained by measuring different pavement distresses on the national road network in the Osijek-Baranja County.

Statistical analysis of the output results confirmed a high coefficient of determination and correlation between the actual data and the data assessed by the neural network. In $95 \%$ of the cases, the neural network correctly determined the maintenance strategy, while the percentage of forecasting accurate values of the global performance index was $87 \%$.

From the above analysis, it can be concluded that the proposed neural network is appropriate for the classification of data on pavement condition to determine the global performance index and optimal maintenance 
strategy. Its implementation in a pavement management system would provide a high quality tool that will facilitate decision-making in the selection of maintenance procedures and the rehabilitation of pavement in individual sections, sub-segments or segments of the national road network in the Republic of Croatia.

The data base used in this study was yearly updated with new data for measured technical parameters and applied maintenance methods. Further research is intended to examine possible application of neural network for prediction of pavement condition during its remaining lifetime on the basis of data gathered in a five year period. Further research is aimed at evaluating the possibility for using neural network results for planning, estimating and scheduling future pavement maintenance activities on national road network.

\section{REFERENCES}

[1] Rukavina, T. \& Ožbolt, M. (2009). Pavement Management System - Data Collection, Management of Transport Infrastructure. Transportation Days 2009, Faculty of Civil Engineering of University of Zagreb, Zagreb, 95-175. (in Croatian)

[2] Paterson, W. (1987). Road Deterioration and Maintenance Effects: Models for planning and Management, Baltimore: The John Hopkins University press.

[3] Zaniewski, J. P. \& Mamlouk, M. S. (1996). Preventive Maintenance Effectiveness - Preventive Maintenance Treatments. Federal Highway Administration, Report No. FHWA-SA-96-027, Retrieved from https://www.fhwa.dot.gov/pavement/pubs/013734.pdf

[4] Sundin, S. \& Braban-Ledoux, C. (2001). Artificial Intelligence - Based Decision Support Technologies in Pavement Management. Computer-Aided Civil and Infrastructure Engineering, 16, 143-157. https://doi.org/10.1111/0885-9507.00220

[5] Adeli, H. (2001). Neural Networks in Civil Engineering: 1989-2000. Computer-Aided Civil and Infrastructure Engineering, 16, 126-142. https://doi.org/10.1111/0885-9507.00219

[6] Bosurgi, G. \& Trifir, F. (2005). A model based on artificial neural networks and genetic algorithms for pavement maintenance management, International Journal of Pavement Engineering, 6(3), 201-209. https://doi.org/10.1080/10298430500195432

[7] Alsugair, A. M. \& Al-Qudrah, A. A. (1998). Artificial Neural Network Approach for Pavement Maintenance. Journal of Computing in Civil Engineering, 12(4), 249-255. https://doi.org/10.1061/(ASCE)0887-3801(1998)12:4(249)

[8] Eldin, N. N. \& Senouci, A. B. (1995). A Pavement Condition-Rating Model Using Backpropagation Neural Networks. Microcomputers in Civil Engineering, 10, 433441. https://doi.org/10.1111/j.1467-8667.1995.tb00303.x

[9] van der Gryp, A., Bredenhann, S. J., Henderson, M. G., \& Rohde, G. T. (1998). Determining the visual condition index of flexible pavements using artificial neural networks. Fourth International Conference on Managing Pavements, Durban, South Africa, 115-129. Retrieved from http://citeseerx.ist.psu.edu/viewdoc/download?doi=10.1.1.6 $59.5697 \&$ rep $=$ rep $1 \&$ type $=$ pdf

[10] Thube, D. T. (2011). Artificial Neural Network (ANN) Based Pavement Deterioration Models for Low Volume Roads in India. International Journal of Pavement Research and Technology, 5(2), 115-120. Retrieved from http://www.ijprt.org.tw/reader/pdf.php?id=223

[11] Yang, J., Lu, J. J., Gunaratne, M., \& Xiang, Q. (2003). Forecasting overall pavement condition with neural networks - an application on Florida Highway Network. Transportation Research Record 1853, Paper No. 03-3441, 3-12. https://doi.org/10.3141/1853-01

[12] Huang, Y. \& Moore, R. K. (1997). Roughness level probability prediction using artificial neural networks. Transport Research Record 1592, Paper No. 970419, 89-97. https://doi.org/10.3141/1592-11

[13] Lin, J. D., Yau, J. T., \& Hsiao, L. H. (2003). Correlation analysis between international roughness index (IRI) and pavement distress by neural network. $82^{\text {nd }}$ Annual Meeting of the Transportation Research Board, Washington, DC, USA, Retrieved from https://www.researchgate.net/ profile/Jyh-Dong_Lin/publication/228848218_Correlation analysis_between_international_roughness_index_IRI_and _pavement_distress_by_neural_network/links/02e-7e $52 \mathrm{f} 385$ af7c205000000/Correlation-analysis-between-internationalroughness-index-IRI-and-pavement-distress-by-neuralnetwork.pdf

[14] Mazari, M. \& Rodriguez, D. D. (2016). Prediction of pavement roughness using a hybrid gene expression programming-neural network technique. Journal of Traffic and Transportation Engineering, 3(5), 448-455. https://doi.org/10.1016/j.jtte.2016.09.007

[15] Flintsch, G. W., Zaniewski, J. P., \& Delton, J. (1996). Artificial neural network for selecting pavement rehabilitation projects. Transport Research Record 1524, 185-193. https://doi.org/10.3141/1524-22

[16] Abdelrahim, A. M. \& George, K. P. (2000). Artificial neural network for enhancing selection of pavement maintenance strategy. Transport Research Record 1699, Paper No. 000133, 16-22. https://doi.org/10.3141/1699-03

[17] Mosa, A. M. (2017). Neural network for flexible pavement maintenance and rehabilitation. Applied Research Journal, 3(4), 114-129. Retrieved from https://www.researchgate.net/ profile/Ahmed_Mosa9/publication/319254372_NEURAL NETWORK_FOR_FLEXIBLE_PAVEMENTS_MAINTE NANCE_AND_RĒHABILITAT̄TON/links/599ē044045851 574f4b35bc2/NEURAL-NETWORK-FOR-FLEXIBLEPAVEMENTS-MAINTENANCE-ANDREHABILITATION.pdf

[18] Gabely, H. R. (2015). Pavement maintenance decision model using artificial neural networks. Master thesis, Faculty of Engineering, Fayoum University, Fayoum, Egypt. Retrieved from http://www.fayoum.edu.eg/thesesdatabase/abstracts/ PAVEMENTMAINTENANCE.pdf

[19] Ceylan, H., Bayrak, M. B., \& Gopalakrishnan, K. (2014). Neural networks applications in pavement engineering: A recent survey. International Journal of Pavement Research and Technology, 7(6), 434-444. https://doi.org/10.6135/ijprt.org.tw/2014.7(6).434

[20] Apanavičienè, R. \& Juodis, A. (2003). Construction projects management effectiveness modelling with neural networks. Journal of Civil Engineering and Management, 9(1), 59-67. https://doi.org/10.1080/13923730.2003.10531302

[21] Roberts, C. A. \& Attoh-Okine, N. O. (1998) A comparative analysis of two artificial neural networks using pavement performance prediction. Computer-Aided Civil and Infrastructure Engineering, 13, 339-348. https://doi.org/10.1111/0885-9507.00112

[22] Gershenson, C. (2014, March 10). Artificial Neural Networks for Beginners. Retrieved from http://www.academia.edu/279017/Artificial_Neural_Netwo rks_for_Beginners

[23] Saduf, M. A. W. (2013). Comparative Study of Back Propagation Learning Algorithms for Neural Networks. International Journal of Advanced Research in Computer Science and Software Engineering, 3(12), 1151-1156. Retrieved from https://pdfs.semanticscholar.org/c804/ 342a840fc2eb3a3415e249b67145019c5b55.pdf 
[24] Suman, S. K. \& Sinha, S. (2012). Pavement condition forecasting through artificial neural network modelling. International Journal of Emerging Technology and Advanced Engineering, 2(11), 474-478. Retrieved from http://citeseerx.ist.psu.edu/viewdoc/download?doi=10.1.1.4 $14.21 \&$ rep $=$ rep $1 \&$ type $=$ pdf

[25] Litzka, J., Leben, B., La Torre, F., Weninger-Vycudil, A., Antunes, M., Kokot, D., Mladenović, G., Brittain, S., \& Viner, H. (2008). The way forward for pavement performance indicators across Europe. COST Action 354 Performance Indicators for Road Pavements. Final Report. Retrieved from http://cost354.zag.si/fileadmin/cost354/ 1fr/COST354_FinalReport_05062008.pdf

[26] Internal Guidelines of Croatian Roads (in Croatian, available on request)

[27] Marcelino, P., Antunes, M., \& Fortunato, E. (2018). Comprehensive performance indicators for road pavement condition assessment. Structure and Infrastructure Engineering, 1-13. https://doi.org/10.1080/15732479.2018.1446179

[28] Kuvačić, B., Rukavina, T., Alerić, D., \& Magdalenić, B. (2017). The Pavement management system on Croatian motorways. World Conference on Pavement and Asset Management, WCPAM2017, Milano, Italy. Retrieved from https://www.researchgate.net/profile/Tatjana_Rukavina/pub lication/319204830_The_Pavement_management_system on Croatian motorways/links/599add220f7e9b892 bacfc23/ The-Pavement-management-system-on-Croatianmotorways.pdf

[29] Dragovan, H. (2011). Application of neural network in pavement management, Master Thesis, University of Zagreb, Faculty of Civil Engineering, Zagreb. (in Croatian)

\section{Contact information:}

Josipa DOMITROVIĆ, PhD, assistant professor

Faculty of Civil Engineering of University of Zagreb

Kačićeva 26, 10000 Zagreb, Croatia

E-mail: jdomitrovic@grad.hr

Hrvoje DRAGOVAN, MSc

RDC d.0.0.

Trg Lava Mirskog 1/3, 31000 Osijek, Croatia

E-mail: hrvoje.dragovan@rdc.hr

Tatjana RUKAVINA, PhD, full professor

Faculty of Civil Engineering of University of Zagreb

Kačićeva 26, 10000 Zagreb, Croatia

E-mail: rukavina@grad.hr

Sanja DIMTER, PhD, full professor

J. J. Strossmayer University of Osijek, Faculty of Civil Engineering

Vladimira Preloga 3, 31000 Osijek, Croatia

E-mail: sdimter@gfos.hr 